\title{
O PAPEL DA LEITURA NA CONSTRUÇÃO DA LITERATURA E DA RELIGIOSIDADE
}

\author{
Jorgemar Teixeira ${ }^{1}$
}

\begin{abstract}
Resumo: Este artigo tem a intensão lançar um olhar sobre a Leitura, a Religiosidade e a Literatura. Pretende-se demonstrar como a Religiosidade é um tema recorrente dentro dos clássicos da Literatura ocidental. Os autores, aqui mencionados, utilizaram-se do tema Religiosidade de maneira semelhante aos autores que os antecederam, formando, de certa maneira, uma relaçáo entre os textos e a temática da Religiosidade. A Leitura, das obras consideradas clássicas, também influenciou os autores e as suas obras que vieram a se tornar referência literária. Dessa forma, percebe-se que as obras literárias se modificam em muitos aspectos, mas a temática da Religiosidade parece persistir na Literatura.
\end{abstract}

Palavras-chave: Leitura, Literatura, Religiosidade.

\section{THE ROLE OF READING IN THE CONSTRUCTION OF LITERATURE AND RELIGIOSITY}

\begin{abstract}
This article intends to take a look at Reading, Religiosity, and Literature. It is intended to demonstrate how Religiosity is a recurring theme within the classics of Western Literature. The authors mentioned here used the theme of Religiosity in a similar way to the authors who preceded them, forming, in a certain way, a relationship between the texts and the theme of Religiosity. Reading among the works considered classic has also influenced the authors and their works that have become a literary reference. Hence, it is clear that literary works change in many ways, but the theme of Religiosity seems to persist in Literature.
\end{abstract}

Keywords: Reading, Literature, Religiosity.

1 Possui mestrado em Letras, Cultura e Regionalidade pela Universidade de Caxias do Sul (2017), especialização em Metodologia de Ensino de Língua Portuguesa e Literatura pelo Centro Universitário Leonardo Da Vinci (2012), graduação em Letras - Português/Espanhol pela Universidade do Extremo Sul Catarinense (2008) e graduação em Letras - Portuguêe/Inglês pela Universidade do Extremo Sul Catarinense (2002). Atualmente é professor do Instituto Federal de Educaçáo, Ciência e Tecnologia do Rio Grande do Sul e doutorando em Letras, Leitura e Processos Culturais pela Universidade de Caxias do Sul. 


\section{INTRODUÇÃO}

Entende-se que a nossa sociedade vive em conformidade com os elementos culturais que foram estratificados ao longo de sua existência. Muitos são esses princípios, como a linguagem, a arte, a religiosidade, a vestimenta, a cultura. Acredita-se que a leitura tem um papel fundamental no desenvolvimento desses elementos de cultura, sobretudo para a literatura e a religiosidade. A literatura, como manifestação artística e de linguagem, pode servir para educar, entreter, mostrar novos pontos de vista, criticar a sociedade, criar realidades diferentes. A religiosidade desempenha também um papel educativo, pode entreter, mostra concepçóes diferentes, censura certos comportamentos sociais, intenta implementar percepçóes de espiritualidade.

Esses dois componentes da cultura social, a literatura e a religiosidade, são relevantes para que se possa ter uma leitura mais abrangente da nossa coletividade. Elas, há muito tempo, confundem-se, ou melhor, mesclam-se em textos, sejam eles religiosos ou literários. Isso se dá, talvez, porque a religiosidade está culturalmente imbricada na história da humanidade desde seu início. Muitas culturas têm a literatura e a religiosidade em seu ambiente de interação, inclusive as ágrafas, nas quais esses fenômenos frequentemente se manifestam nas formas orais. Seja para contar um fato ou para narrar uma história com temática moral, esses fundamentos sociais estáo presentes. Dir-se-ia que nascendo a linguagem em determinada coletividade, então surgiriam a literatura e a religiosidade, como consequência e transformação do grupo social em questão. Contudo, o contato entre literatura clássica e religiosa se expandiu com o advento da leitura, seja ela em grupo ou individual.

De um ponto de vista cronológico, os primeiros livros do cânon ocidental são aqueles atribuídos a Homero. São considerados monumentos artísticos que embasam toda tradição literária posterior. Nesses poemas épicos, observam-se intervençôes dos deuses gregos nas mais diversas situaçóes, inclusive tomando partido na guerra de Troia, durante a qual alguns deuses ficaram do lado dos troianos, outros do lado dos gregos e somente dois mantiveram-se neutros: Zeus e Hades. Ao se deparar com as divindades gregas no poema homérico, logo percebe-se que a religiosidade está presente nos primeiros clássicos da nossa literatura. Assim, a literatura e a religiosidade, por meio da narraçáo ou da leitura, servem-se uma da outra, alterando, assim, a cultura da sociedade em que estáo inseridas.

Os hebreus utilizaram-se e ainda fazem uso da leitura para transmitir sua cultura e seus ensinamentos para o seu povo por meio da Bíblia Hebraica. Também conhecida como Tanakh, a Bíblia Hebraica é o conjunto de livros que tem início em Bereshit (Gênesis) e termina em Divrê-Hayamim (Crônicas). São 24 livros divididos em três partes: Torah (Lei), com cinco livros; Neviim (Profetas), com oito livros; e Kethuvim (Escrituras Sagradas), com 11 livros. A Tanakh é semelhante ao conjunto de livros que os cristãos intitularam de Antigo Testamento, porém há diferenças quanto às divisões e ao número de livros. Para os católicos o Antigo Testamento é formado por 46 livros, já para os protestantes são 39. O Novo Testamento são 
as escrituras que relatam a vida e os atos de Jesus de Nazaré e de seus apóstolos e inclui um livro chamado Apocalipse (Revelação) que traz, segundo os cristãos, as revelaçóes do que viria a acontecer com os homens e seu planeta.

A Tanakh, atribuída a Moisés e outros escritores, utilizou-se de vários elementos literários para descrever as instruçóes, os ensinamentos, as leis para o povo hebreu. Por se tratarem de escritores da mesma cultura, assim também o fizeram os autores do Novo Testamento, aproveitando-se dos gêneros usados na Bíblia Hebraica. Então, a leitura do Antigo Testamento influenciou os costumes dos autores do Novo Testamento bíblico, o que refletiu em suas produçóes literárias. Há nos dois testamentos os mais variados tipos literários. Dessa forma, para que haja uma leitura e estudos dos textos bíblicos mais arejados e com maior embasamento cultural, necessita-se ter consciência de que, na Bíblia, como a conhecemos hoje, tem-se uma diversidade de gêneros literários, tais como: o didático, o profético, o poético, o apocalíptico, o jurídico, o epistolar. Cássio Murilo Dias Silva fornece proveitosa reflexão sobre a presença dos gêneros literários na Bíblia em seu livro Leia a Bíblia como Literatura:

Falar em "gênero literário" exige que se façam algumas observaçôes prévias. Em primeiro lugar, o termo "gênero literário" corre o risco de fazer esquecer que boa parte do material bíblico surgiu como tradição oral, isto é, antes de se tornarem textos, relatos e ensinamentos eram transmitidos de boca em boca, não só como atividade lúdica e estética, mas também como forma de transmitir cultura, orientaçóes estéticas e conteúdo de fé. Por isso, embora o estudo de gêneros literários baseie-se no material escrito, não se pode apagar o estágio anterior ao processo de transcrição.

Segundo, embora boa parte dos "gêneros literários" tenha esquemas relativamente fixos, esta não é uma regra universal. Há textos que possuem um estilo ou uma índole comum, mas não seguem o mesmo modelo. Com efeito, também esta é uma herança do período de transmissão oral.

Terceiro, o gênero literário "puro" existe só na abstração. Toda vez que um modelo é empregado, ele sofre influências do contexto e apresenta alteraçóes, seja na sua forma, seja na sua finalidade. Há também textos híbridos, isto é, uma mesma perícope pode ser formada pela justaposição de dois gêneros literários distintos.

Quarto, cumpre observar que os mesmos gêneros literários são utilizados tanto no Antigo como no Novo Testamento. (SILVA, 2007, p. 41-42)

Dessa forma, percebe-se que os livros bíblicos estão inseridos em uma cultura específica, são obras interdependentes e estão em muitos momentos fazendo referências a outros textos, relatos, instruçóes orais e escritos. Assim, a leitura dos textos anteriores têm função basilar na construção dos novos textos religiosos.

\section{AUERBACH LÊ A BÍBLIA HEBRAICA E HOMERO}

Auerbach, em seu livro Mimesis, faz uma interessante correlação entre um texto homérico e um da Bíblia Hebraica. Ele, ao comparar as duas composiçóes, demonstra algumas das diferenças que cada cultura imprime em sua literatura. $\mathrm{O}$ título que o autor dá a esse texto é "A Cicatriz de Ulisses". O poema de Homero é 
contrastado com o relato do sacrifício de Isaac presente em Gênesis 22. Ao confrontar os textos, Auerbach afirma que "Não é fácil, portanto, imaginar contrastes de estilos mais marcantes que estes, que pertencem a textos igualmente antigos e épicos." (AUERBACH, 1946, p. 9) Uma diferença curiosa é como cada autor narra a sua divindade e suas personagens.

A observação do texto eloísta mostra-nos que a expressão pode ser empregada mais ampla e profundamente. Evidencia-se que até a personagem principal pode ser apresentada como carregada de segundos planos: Deus sempre o é na Bíblia, pois não é, como Zeus, apreensível na sua presença; só "algo" dele aparece em cada caso, ele sempre se estende para as profundidades. Mas os próprios seres humanos dos relatos bíblicos são mais ricos em segundos planos do que os homéricos; eles têm mais profundidade quanto ao tempo, ao destino e a consciência. (AUERBACH, 1946, p. 9)

Assim, pela leitura de Auerbach, percebe-se o tipo de narraçáo que a cultura hebraica e a grega têm de suas respectivas divindades. Ao comentar que Deus para os hebreus sempre o é, ele quer dizer que a sua divindade sempre está presente, porém não é apreensivel, ou seja, não se pode compreendê-la além do que ela quer que se compreenda de si mesma, pois é um ser espiritual e não está sujeito às vontades humanas. Um exemplo da imaterialidade do Deus dos hebreus é o tetragrama YHVH, que representa a forma escrita de seu nome, porém é impronunciável, justamente para demonstrar a sua intangibilidade. Ao contrário, Zeus é apreensível na sua presença, dessa forma essa divindade é mais humana, está sujeita às necessidades humanas, tanto o é que tem filhos semideuses devido às suas relaçôes com mulheres mortais.

Os próprios seres humanos são diferentes nos dois contextos. Talvez porque os homens do texto hebraico, na perspectiva de Auerbach, possuam maior riqueza de segundos planos e maior profundidade de tempo, destino e consciência, se comparados aos homéricos.

O mais importante, contudo, é a multiplicidade de camadas dentro de cada homem; isto é dificilmente encontrável em Homero, quando muito na forma da dúvida consciente entre dois possíveis modos de agir; em tudo o mais a multiplicidade da vida psíquica mostra-se nele só na sucessão, no revezamento das paixóes; enquanto que os autores judeus conseguem exprimir as camadas simultaneamente sobrepostas da consciência e do conflito entre as mesmas. (AUERBACH, 1946, p. 10)

Há um provérbio judeu segundo o qual a Torah tem 70 faces, que pode contribuir para explicar a referida multiplicidade de camadas dentro de cada homem. Setenta é um número que pode designar infinitas vezes para o povo judeu e, ao dizer que a Torah tem 70 faces, afirma-se que existe uma infinidade de interpretaçóes, desde que bem embasadas nos textos hebreus. Então, há uma cultura de leitura, releitura e interpretação para os hebreus, que fazem novas observaçóes sobre os mesmos pontos de seus textos, sem desvalidar as compreensóes anteriores, formando assim múltiplas camadas de análises. Eventualmente aí esteja uma das causas das 
diferenças entre um texto evocativo e um texto mais narrativo, o primeiro referindose aos escritos hebreus e o segundo aos homéricos.

As diferenças entre os textos, gregos e hebreus, que Erich Auerbach tenta demonstrar em seu livro, podem indicar algumas particularidades das culturas em questáo. Os dois textos originaram-se da transmissão oral que seus povos conduziam de geração para geração. Então, como Auerbach comenta em sua distinção entre os textos, o grego é mais objetivo, enquanto o hebraico necessita de interpretaçáo mais aprofundada. Talvez, por isso, exista a necessidade de voltar várias vezes ao mesmo texto. As personagens dos poemas homéricos têm conflitos, porém carecem de algo externo para que ecloda a divergência. $\mathrm{Na}$ Tanakh, os tipos são mais complexos, pois além dos conflitos internos, das personagens consigo mesmas, há a interferência de Deus e das pessoas de sua comunidade, gerando ainda mais embates psicológicos, como num circuito. $\mathrm{O}$ autor de Mimesis ainda comenta que o "Velho Testamento, enquanto se ocupa do acontecer humano, domina todos os três âmbitos: lenda, relato histórico e teologia histórica exegética." (AUERBACH, 1946, p. 17-18) Antes disso, ele adverte que, por ser uma escrita mais complexa, a literatura hebraica está mais próxima da história do que os escritos de Homero.

Abraão, Jacó ou até Moisés, têm um efeito mais concreto próximo e histórico do que as figuras do mundo homérico, não por estarem melhor descritos plasticamente - pelo contrário - mas porque a variedade confusa, contraditória, rica em inibiçóes dos acontecimentos internos e externos que a história autêntica mostra não está desbotada na sua representação, mas está ainda nitidamente conservada. (AUERBACH, 1946, p. 17)

Cabe aqui notar que Auerbach, como judeu, conhece os textos da tradição judaica. Desse modo, ele consegue transitar, desembaraçadamente, por escritos que, às vezes, parecem táo complexos para quem náo tem muita intimidade com eles. Essa relação mais estreita com o texto hebreu o faz um crítico literário com uma percepção mais ampla das conexóes textuais que porventura outros textos tenham com as Escrituras Sagradas judaico-cristãs. Contudo, a análise de Auerbach sobre o texto homérico estabeleceu-se sobre a superficialidade das camadas psicológicas dos personagens em ralação aos do texto bíblico. Eliade e Couliano trazem uma contribuição distinta sobre a leitura de literatura e religiosidade, referindo-se aos textos épicos como de Homero.

A literatura geralmente fixa o mito. Tal será o caso das epopeias homéricas, orais na origem mas registradas por escrito nos séculos VII e VI a.C. Homero, Hesíodo e os outros poetas acabam tendo um peso teológico incalculável. (ELIADE; COULIANO, 1990, p. 163, grifo original)

A leitura de textos históricos e religiosos relata que as pessoas prestavam culto e sacrificavam animais em oferenda aos deuses gregos e romanos. Esta também é uma forma de contrastar as culturas hebraicas e greco-romanas, pois os hebreus também faziam oferendas, mas para um Deus único. Diferentemente dos gregos, conforme diálogo entre Fedro e Sócrates, em Diálogos, de Platão. 
Sócrates: - Não convém que façamos uma prece aos deuses daqui antes de nos retirarmos? / Fedro: - Sim, tens razão. / Sócrates: — Divino Pã e vós deuses outros destas paragens! Dai-me a beleza da alma, a beleza interior e fazei com que meu exterior se harmonize com essa beleza espiritual. (PLATÃO, 1996, p. 183)

As diferenças culturais davam legitimidade para que as comunidades pudessem se estabelecer como grupos sociais coesos. Afirmando-se como grupo social, elas formavam regras particulares de convívio e também suas leis. Para os hebreus, as normas estavam nos 613 mandamentos da Torah, o que conferia à literatura judaica a função de educar, instruir, legislar, aplicar a lei. Assim, tem-se uma ideia do quão importante era a leitura desses livros para aquela comunidade. Ainda hoje eles servem para os praticantes do judaísmo, obviamente, mas também como fonte de estudos para qualquer pessoa interessada sobre a cultura ocidental, já que o ocidente também se desenvolveu sob os fundamentos judaico-cristãos.

Percebe-se que há diferenças culturais intrínsecas entre os poemas de Homero e os textos bíblicos. Essa distinçáo de formas de escrever não se deve apenas à diferença de suportes - texto poético e texto religioso - e à distância temporal, mas ocorre também em função do distanciamento regional e da religiosidade que os distingue. É possível pensar, com Arendt, "que uma região cultural é composta por especificidades (assim, no plural) materiais e imateriais - regionalidades que armam um tecido complexo e flexível, o qual se mostra outro a cada novo olhar." (ARENDT, 2012, p. 89) Nesse sentido, ainda que a conceituaçáo de Arendt refirase a um contexto distinto, pode-se perceber como esse mesmo tecido complexo e flexivel delimita e distancia a cultura hebraica da cultura grega, demarcando as especificidades que cada grupo apresenta em relação à maneira pela qual prestam culto às suas divindades e as representam em textos escritos.

\section{VIRGÍLIO LÊ HOMERO}

O poema Eneida de Virgílio também é um escrito, assim como o Novo Testamento, que se ampara em outros mais antigos. Virgílio começa a compor sua maior obra no ano 31 a.C., ou seja, por volta de oito séculos depois das duas grandes composiçóes de Homero, Odisseia e Ilíada. A primeira parte de Eneida reporta-se aos eventos sucedidos na Odisseia, enquanto a segunda seção remete aos feitos manifestados em Ilíada. A abertura da composição do poeta romano iniciase nos instantes finais em que Troia perde a guerra para a Grécia. Eneias, que é o personagem principal de Eneida, manifesta-se tanto em Iliada como em Eneida. Neste último ele casa-se com a descendente do rei Latino, Lavínia, que, conforme uma profecia, deveria desposar um estrangeiro para formar um povo vigoroso que governaria outros povos. Assim, Virgílio redige nos seus versos a grandiosidade de Roma inspirado na leitura das obras atribuídas a Homero.

A intertextualidade entre o poema do escritor romano e os de Homero é óbvia e proposital, pois Virgílio buscou por meio de sua epopeia enaltecer o império romano. Alguns diriam que Virgílio se aproveitou mais do que deveria da leitura 
dos escritos de Homero para compor seu poema, mas Cardoso argumenta que "a Eneida, porém, não pode ser considerada como cópia vulgar dos poemas homéricos. Mantendo pontos que haviam sido explorados na poesia da Grécia, Virgílio soube ser original e sobretudo romano." (1989, p. 24). Entende-se que o escritor de Eneida, enlevado pela leitura dos poemas homéricos, serviu-se dos textos reconhecidos para imprimir os costumes de seu povo numa composição a altura de seus feitos.

Percebe-se, pois, como as obras mencionadas mantêm relaçóes entre si e fomentam diálogos entre distintos espaços e culturas. A repetição do tema religiosidade que é um dos motes deste texto e que se apresenta tanto nos poemas de Homero como nos de Virgílio, a interferência dos deuses nos acontecimentos pelos quais os heróis dos poemas passam, é como uma ponte que vai de Roma à Grécia, ligando uma cultura à outra, apesar do tempo e do espaço bastante distanciados. Assim, a leitura se faz como pedra angular dessa ponte mágica que movimenta a cultura mundial.

Como na Grécia, os romanos acreditavam e cultuavam vários deuses. As divindades romanas tinham as mesmas características das potestades gregas. Dirse-ia que são os mesmos deuses, porém com nomes diferentes. Virgílio, ao escrever Eneida, baseia-se nas epopeias de Homero, compondo, assim, um texto inspirado na poesia épica clássica grega. Embora os poemas de Virgílio e Homero estejam distanciados no tempo, a religiosidade grega, por meio da leitura, influencia a literatura e, consequentemente, a cultura romana da época. Bakhtin auxilia na compreensão do que se pretende aqui demonstrar,

No campo da cultura, a distância é a alavanca mais poderosa de compreensão.
A cultura do outro só se revela com plenitude e profundidade, aos olhos de
outra cultura. Um sentido só revela as suas profundidades encontrando-se e
contactando com o outro, com o sentido do outro, entre eles começa uma
espécie de diálogo que supera o fechamento e unilateralidade, desses sentidos,
dessas culturas (BAKHTIN, 2006, p. 366).

A intertextualidade parece ser inerente a todo e qualquer texto, seja ele oral ou escrito, pois se assim não fosse, se não houvesse um conhecimento prévio de determinados conceitos e conteúdos, que se pretende abordar de forma dialógica entre os interlocutores, seria mais difícil a compreensão do que se pretendesse vulgarizar e, consequentemente, a comunicação talvez se tornasse mais complexa. $\mathrm{E}$, nesse caso, no que se refere ao texto escrito, grande propagador da cultura no mundo, tem-se na leitura o veículo principal da intertextualidade.

Interessante notar que, como foi mencionado anteriormente, a sociedade vive conforme a estratificação dos seus costumes ao longo do tempo, contudo deveríamos acrescentar que a literatura, por intermédio da leitura praticada por leitores afastados no tempo e no espaço, também se transforma e se renova em conformidade com os elementos culturais que vão sendo sedimentados em seu percurso contínuo. De maneira semelhante comentou Bourdieu num debate com Chartier sobre práticas de leitura: "Quando o livro permanece e o mundo em torno dele muda, o livro muda." (BOURDIEU, 1996, p. 250) 
Pode-se ainda incluir nessa perspectiva de mudança de hábitos de leitura o que Lyons comenta, em A palavra impressa: "O aprendizado da escrita e da leitura a partir da Bíblia era prática comum nos países protestantes do século XIX." (LYONS; LEAHY 1999, p. 180) Assim, os textos bíblicos que antes serviam para educar os judeus e os cristãos em conformidade com suas regras sociais desde alguns milênios, a Bíblia serviria mais tarde para o ensino da leitura. Dessarte, o texto religioso não auxiliaria somente para orientar as normas que fundamentam uma sociedade com bases religiosas, mas também para ser o veículo que levaria os iletrados desse grupo social para o mundo da leitura e da escrita.

\section{DANTE LÊ VIRGÍLIO}

Inicialmente inspirado pela leitura das obras de Homero, Virgílio viria influenciar Dante Alighieri, leitor de sua obra, em A Divina Comédia, pois os autores também sáo leitores. (DARNTON, 1990) Porém, no caso de Dante, as mudanças culturais da sua época, sobretudo no que se refere à religiosidade, não lhe permitiam cultuar os deuses greco-romanos como outrora, da forma que Homero e Virgílio expuseram em seus escritos. Na sociedade italiana dos séculos XIII e XIV, vigorava a crença em um Deus único, em conformidade com o cristianismo, que, por sua vez, tem fundamentação no judaísmo. Ou seja, no caso de Dante, que era italiano e que estava distante de Virgílio por mais de dez séculos, identifica-se a sobreposição das quatro culturas citadas até então: a grega, a romana, a judaica e a cristã.

Essas culturas, sedimentadas como estão na obra de Dante, faz-se possível devido a história de leitura de cada autor dos textos das referidas culturas. Dessa forma, logo no início de sua principal obra, A Divina Comédia, notam-se indícios de referências a Eneias, herói do poema Eneida, de Virgílio:

"Poeta, decantei feitos do justo / Filho de Anquises, que de Tróia veio / Depois
que Ílio soberbo foi combusto / "Mas porque tornas da tristeza ao meio?
/ Porque não vais ao deleitoso monte, / Que o prazer todo encerra no seu
seio?" "-Oh! Virgílio, tu és aquela fonte / Donde em rio caudal brota a
eloqüência?" / Falei, curvando vergonhoso a fronte. _ / "Ó dos poetas lustre,
honra, eminência! / Valham-me o longo estudo, o amor profundo / Com
que em teu livro procurei ciência! "És meu Mestre, o modelo sem segundo;
/ Unicamente és tu que hás-me ensinado / O belo estilo que honra-me no
mundo. (ALIGHIERI, 2006, p. 28-29)

Ao fazer de Virgílio um de seus personagens em seu relevante trabalho, Dante o coloca em um patamar significativo. Ao referi-lo como mestre dos poetas, Alighieri aparenta demonstrar que, como poeta, tinha em Virgílio um artista que desempenhara um papel determinante em sua formação de leitura e composição. Interessante notar que o "Mestre dos poetas" conduzira Dante em sua "viagem astral" somente durante o percurso que foi do Inferno ao Purgatório, pois como Virgílio não fora batizado por haver nascido antes de Cristo, não poderia entrar no Paraíso, conforme a crença cristã da época. 
Essa viagem que Dante fizera ao Inferno, reconhecendo alguns personagens de sua cultura, o protagonista do poema Eneida, de Virgílio, também o fizera, porém, como as culturas eram distintas, Eneias não passou pelo inferno, purgatório e pelo paraíso. Quando Eneida foi escrito não havia o cristianismo, entáo, Eneias foi ao reino dos mortos, onde encontrou Anquises, seu pai. Contudo, antes de realizar a excursão, Eneias teve que pedir permissão à sacerdotisa de Apolo para peregrinar no mundo dos mortos. Nota-se, dessa forma, que Dante construiu seu texto dialogando com o texto de Virgílio, porém teve que adaptar o enredo de seu poema em conformidade com a cultura de seu povo e de sua época. Como o cristianismo era a religiáo predominante na Itália do século XIV e tinha papel predominante no pensamento e nos saberes locais, compreende-se que seria custoso para o autor da Divina Comédia passar ao largo da religião cristã na sua produção artística.

Como está claro na Divina Comédia, os personagens que aparecem no livro influenciaram, de certa forma, a vida do autor, que situa as pessoas conforme suas relações para com elas. Os poetas gregos e romanos, os quais faziam parte da sua história de leitura, admirava e que haviam nascido antes de Cristo, estavam no Limbo, que ficava no primeiro círculo do Inferno. É este o lugar para onde vão, quando morrem, as crianças que não foram batizadas e aqueles que não pecaram antes da vinda de Cristo, conforme comenta Virgílio no poema de Dante.

\footnotetext{
"Conhecer" - meu bom Mestre diz — "não queres / Quais são os que assim vês ora sofrendo? / Antes de avante andar convém saberes / Que não pecaram: boas obras tendo / Acham-se aqui; faltou-lhes o batismo, / Portal da fé, em que és ditoso crendo. / "Na vida antecedendo o Cristianismo, / Devido culto a Deus nunca prestaram: / Também sou dos que penam neste abismo, / "Por tal defeito — os mais não nos mancharam — / Perdemo-nos: a pena é desesperança, / Desejos, que para sempre se frustraram." (ALIGHIERI, 2006, p. 41)
}

Há nove círculos no Inferno, segundo o poema de Alighieri. O Limbo estava no primeiro círculo, consoante a introdução do canto IV do Inferno: "Dante baixa com Virgílio ao primeiro círculo do inferno, onde demora o Limbo" (ALIGHIERI, 2006, p. 40). Para o segundo círculo iriam as pessoas que cometiam os pecados menos graves. No terceiro ficavam os que praticavam transgressóes piores que as executadas pelas pessoas do segundo círculo e assim sucessivamente, até chegar ao derradeiro círculo, reservado aos piores seres. Dentre os quais, estavam na parte mais baixa do Inferno Judas Iscariotes, o discípulo que entregou Jesus Cristo por trinta moedas de prata, e Lúcifer, o anjo que se rebelou e traiu a Deus. Dante considerava a traição como o pior pecado que uma pessoa pudesse cometer, por isso coloca os traidores no precipício derradeiro do inferno.

O autor da Divina Comédia utilizou de elementos culturais próprios de seu tempo para escrever sua obra, dentre os quais a religiosidade, que em seu poema tem papel preponderante. Além da religião ser parte integrante de todo o texto, no qual ela parece ser o fio condutor, a religiosidade também serve como pano de fundo para que o poeta faça críticas a todos os setores da sociedade italiana náo só de sua época, mas também de outras. Por unir religiosidade, substância cultural que 
até hoje vige fortemente na sociedade mundial, a literatura que, entre outras coisas, analisa as dinâmicas sociais de grupos e indivíduos, a leitura da Divina Comédia teve grande impacto no pensamento ocidental e influenciou muitos autores, certamente contribuindo para consolidar a aproximação desses elementos: religião e literatura.

\section{LEITURA, LITERATURA E RELIGIOSIDADE NO BRASIL}

A Carta de Pero Vaz de Caminha, que para Bosi "significou uma autêntica certidão de nascimento [...] dando notícia da terra achada, insere-se em um gênero copiosamente representado durante o século XV em Portugal e Espanha: a literatura de viagens." (BOSI, 1994, p. 14) No entanto, mais do que literatura de viagens, essa "certidão de nascimento", contendo várias referências religiosas, sobretudo ao cristianismo, inscreve-as nas letras brasileiras desde seu início. A começar pelo nome da cidade da qual as embarcaçóes saíram rumo ao novo destino: Belém, cidade da partida das terras portuguesas, também é o nome do local onde Jesus de Nazaré teria nascido. Ao chegarem às terras brasileiras, os navegadores avistaram um monte, e, por aproximarem-se do período da Páscoa, festa judaica e cristã, nomearam-no de Monte Pascoal. Do mesmo modo, deram um nome cristáo para a nova terra encontrada.

Neste mesmo dia, a horas de véspera, houvemos vista de terra! a saber, primeiramente de um grande monte, muito alto e redondo; e de outras serras mais baixas ao sul dele; e de terra chã, com grandes arvoredos; ao qual monte alto o capitáo pôs o nome de $\mathrm{O}$ Monte Pascoal e à terra A Terra de Vera Cruz! (CAMINHA, 1963, p. 02)

Terra da Verdadeira Cruz, esse foi o primeiro nome dado ao Brasil pelos navegantes portugueses, o que indica o desejo dos colonizadores de estabelecer uma cultura baseada em uma crença católica.

Parece-me gente de tal inocência que, se nós entendêssemos a sua fala e eles a nossa, seriam logo cristãos, visto que não têm nem entendem crença alguma, segundo as aparências. E portanto se os degredados que aqui hão de ficar aprenderem bem a sua fala e os entenderem, não duvido que eles, segundo a santa tenção de Vossa Alteza, se farão cristáos e hão de crer na nossa santa fé, à qual praza a Nosso Senhor que os traga, porque certamente esta gente é boa e de bela simplicidade. E imprimir-se-á facilmente neles qualquer cunho que the quiserem dar, uma vez que Nosso Senhor lhes deu bons corpos e bons rostos, como a homens bons. E o Ele nos para aqui trazer creio que não foi sem causa. E portanto Vossa Alteza, pois tanto deseja acrescentar a santa fé católica, deve cuidar da salvação deles. E prazerá a Deus que com pouco trabalho seja assim! (CAMINHA, 1963, p. 09)

Assim, pode-se observar que antes mesmo de haver uma literatura propriamente dita em terras brasileiras, já havia um documento que revelava a história de leitura de Caminha, que representa a cultura dos colonizadores do Brasil, com intensa influência da cultura judaico-cristá permeando as linhas de tal registro, o qual até hoje é indicado como referência inicial para os estudos de leitura 
e literatura em nosso país. Bosi, depois de comentar que a Carta de Caminha é exemplar do gênero de literatura de viagens, observa que há expresso no documento

Espírito observador, ingenuidade (no sentido de um realismo sem pregas) e uma transparente ideologia mercantilista batizada pelo zelo missionário de uma cristandade ainda medieval: eis os caracteres que saltam à primeira leitura da Carta e dão sua medida como documento histórico. (BOSI, 1994, p. 14)

Por viés semelhante, pode ser examinada a poesia de Gregório de Matos, considerado pela crítica literária um dos precursores da literatura brasileira. Alfredo Bosi assinala, comparando Gregório de Matos a Bento Teixeira, que Matos tem a "Poesia muito mais rica [...] que interessa não só como documento da vida social dos Seiscentos, mas também pelo nível artístico que atingiu." (BOSI, 1994, p. 37) Por não poupar ninguém de suas críticas incisivas e, muitas vezes, sarcásticas, o poeta ficou conhecido pela alcunha "Boca do Inferno". Estavam entre as suas "vítimas" os religiosos, os amigos e inimigos, os negros, brancos e mulatos, as autoridades.

Entretanto, é digno de nota que Gregório de Matos não se notabilizou apenas pela poesia satírica, deixando importante legado em poemas sacros e lírico-amorosos. Embora tenha em algumas de suas poesias sacras uma mensagem cristã condigna de um verdadeiro religioso, em outras o poeta explora a temática religiosa com a sua ironia costumeira, fazendo uso de temáticas da filosofia cristá para fazer troças com alguns de seus conceitos. Com efeito, segundo Antonio Candido, "Apesar de conhecido sobretudo pelas poesias burlescas, talvez seja nas religiosas que Gregório alcance a expressão mais alta, manifestando a obsessão com a morte, táo própria da sua época, e nele muito pungente, porque vem misturada à exuberância carnal e ao humorismo satírico, desbragados e saudáveis." (CANDIDO, 2008, p. 102) Assim, percebe-se, também, que na história de leitura de Matos, havia textos que se referiam a cultura judaico-cristã, o que parece ser recorrente nas histórias de leituras de muitos autores da literatura ocidental.

Há muitas formas de abordar o tema religiosidade em textos literários. Gregório optou, em alguns de seus poemas, por fazê-lo de maneira descontraída, mas, para a sua época, talvez tenha sido ousado e audacioso, pois ao tomar assuntos relacionados à doutrina cristá, de modo muitas vezes chistoso, ele estava desafiando uma das instituições mais influentes e poderosas de seu tempo, a Igreja Romana.

Outro dos autores fundamentais do período é Padre Antônio Vieira. Contemporâneo de Gregório de Matos, é considerado por Bosi como nome central da prosa barroca, na qual assoma em primeiro plano a oratória sagrada dos jesuítas. (BOSI, 1994, p. 43) Nascido em Lisboa, Vieira veio ainda menino para a Bahia, onde produziu muitos textos: sermôes, cartas, tratados proféticos. Atribui-se mais de 200 sermóes ao padre autor. Assim como Gregório, Vieira não restringia suas críticas a determinado grupo social da Bahia do século XVII. Ele criticava a tirania dos colonos portugueses, o protestantismo, os pregadores do evangelho, inclusive a Inquisiçáo. Diferentemente de Matos, Vieira embasava seus sermôes nas escrituras sagradas para que seus textos fossem mais persuasivos perante o leitor/ouvinte. Para qualquer assunto que ele fosse abordar haveria uma correlação com o texto bíblico 
que sustentasse toda matéria em questão. É este o caso da última parte de um de seus sermóes mais conhecidos, o Sermão da Sexagésima:

Dir-me-eis o que a mim me dizem, e o que já tenho experimentado, que, se pregamos assim, zombam de nós os ouvintes, e não gostam de ouvir. $\mathrm{Oh}$, boa razão para um servo de Jesus Cristo! Zombem e não gostem embora, e façamos nós nosso ofício! A doutrina de que eles zombam, a doutrina que eles desestimam, essa é a que lhes devemos pregar, e por isso mesmo, porque é mais proveitosa e a que mais hão mister. $\mathrm{O}$ trigo que caiu no caminho comeramno as aves. Estas aves, como explicou o mesmo Cristo, são os demónios, que tiram a palavra de Deus dos coraçóes dos homens: Venit Diabolus, et tollit verbum de corde ipsorum! Pois por que não comeu o Diabo o trigo que caiu entre os espinhos, ou o trigo que caiu nas pedras, senão o trigo que caiu no caminho? [...] (VIEIRA, 1965, parte X)

O Sermão da Sexagésima faz um paralelo com a Parábola do Semeador, a qual está nos evangelhos de Mateus, Marcos e Lucas. Jesus conta que um semeador espalhou as sementes por superfícies de distintas características, mas somente em uma delas os grãos floresceram. Padre Antônio Vieira se aproveitou dessa história e dissertou sobre o tema da pregaçáo em seu tempo e em seu espaço. No entanto, ele explorou a metáfora do semeador e ampliou a interpretação, defendendo que havia problemas no modo de disseminar a palavra de Deus na época. Uma das interpretaçóes sugeridas pelo sermão amplia a perspectiva sobre o problema da infertilidade da terra, advogando que não necessariamente esteja na terra a esterilidade, mas também, provavelmente, no próprio semeador, na maneira como ele realiza o seu trabalho de cultivador. Com a maioria de seus textos pregando a moral evangélica como uma solução possível para os problemas individuais e sociais da sua época e de seu local, os textos de Vieira ficaram conhecidos tanto no Brasil como em Portugal do século XVII. Talvez náo houvesse necessidade de informar que a literatura feita por Padre Antonio Vieira é fundamentada na leitura das obras religiosas judaico-cristãs, sobretudo o Novo Testamento.

\section{CONSIDERAÇÓES FINAIS}

Assume-se, então, que religiosidade, entre outros elementos de cultura, revela-se um tema recorrente na história da leitura do mundo ocidental. Esse assunto também tem influenciado a fisionomia da história da leitura brasileira desde seus primeiros textos, pois, como esforça-se por demonstrar, a sedimentaçáo cultural se reflete na arte, sobretudo na literatura, que também é representação das várias camadas culturais de grupos sociais. O Brasil é um país que tem em sua formação a presença de vários povos, dessa forma, seria natural que múltiplas culturas transbordassem nas leituras de seus textos literários. Muitos autores brasileiros fizeram obras importantes revelando as particularidades de seu povo. E esses aspectos culturais retratados nas obras literárias brasileiras parecem carregar traços modificados dos assuntos abordados nas leituras dos clássicos da literatura ocidental, sobretudo quando se referem ao tema religiosidade. 


\section{REFERÊNCIAS}

ALIGHIERI, Dante. A Divina Comédia. São Paulo: Martin Claret, 2006.

ARENDT, João Claudio. Do outro lado do muro: regionalidades e regióes culturais. Rua [online], Campinas, v. 2, n. 18, 2012.

AUERBACH, Erich. Mimesis: a representação da realidade na literatura ocidental. 4. ed. São Paulo: Perspectiva, 2002.

BAKHTIN, Mikhail. Estética da criação verbal. São Paulo: Martins Fontes, 1997.

BOSI, Alfredo. História concisa da literatura brasileira. São Paulo: Cultrix, 2006.

BOURDIEU, Pierre. Práticas da leitura. Tradução de Cristiane Nascimento. São Paulo: Estação Liberdade, 1996.

CAMINHA, Pero Vaz de. A carta de Pero Vaz de Caminha. Carta a El Rei D. Manuel, Dominus: São Paulo, 1963. Disponível em: <http://www.dominiopublico.gov.br/ download/texto/bv000292.pdf>. Acesso em: 28 dez. 2017.

CANDIDO, Antonio. Letras e ideias no período colonial. In: CANDIDO, Antonio.

Literatura e sociedade: estudos de teoria e história literária. 10. ed. rev. Rio de Janeiro: Ouro sobre Azul, 2008. 99-116 p.

CARDOSO, Zélia Almeida de. A literatura latina. Porto Alegre: Mercado Aberto, 1989.

DARNTON, Robert. O beijo de Lamourette. São Paulo: Companhia das Letras, 1990.

ELIADE, Mircea; COULIANO, Ioan Petru. Dicionário das religióes. São Paulo:

Martins Fontes, 1990.

LYONS, M.; LEAHY, C. A palavra impressa: histórias da leitura no século XIX. Rio de Janeiro: Casa da Palavra, 1999.

PLATÃO. Fedro. In: PLATÃO. Diálogos. 19. ed. Rio de Janeiro: Ediouro, 1996.

SILVA, Cássio Murilo Dias da. Leia a Bíblia como literatura. São Paulo: Loyola, 2007.

VIEIRA, Antônio Vieira. O sermão da Sexagésima. Sermões Escolhidos. v. 2, São Paulo: Edameris, 1965. Disponível em: <http://www.dominiopublico.gov.br/download/texto/ bv000034.pdf>. Acesso em: 28 dez. 2017. 